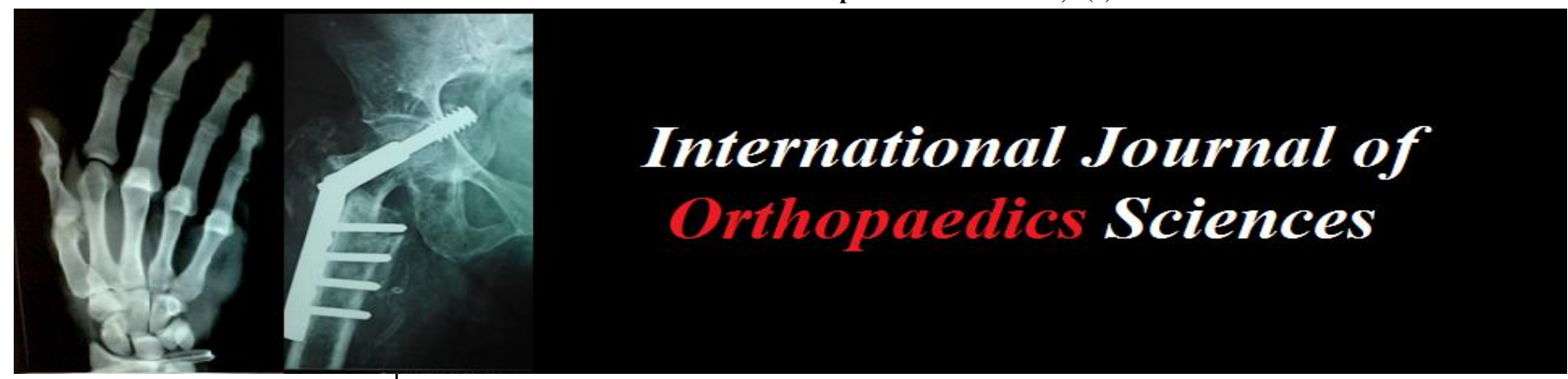

E-ISSN: 2395-1958

P-ISSN: 2706-6630

IJOS 2019; 5(4): 196-199

(C) 2019 IJOS

www.orthopaper.com

Received: 18-08-2019

Accepted: 22-09-2019

Dr. Naik Sandeep

Assistant Professor, Dept of

Orthopaedics Shri B M Patil

Medical College Hospital and

Research Institute BLDE (DU)

Vijyapura, Karnataka, India

Babaleshwar Vinaykumar

Assistant Professor, Dept of

orthopaedics, Shri B M

Patil Medical College Hospital and Research Institute BLDE

(DU) Vijyapura, Karnataka,

India

Nandi Santosh

Professor, Dept of Orthopaedics Shri B M Patil Medical College Hospital and Research Institute BLDE (DU) Vijyapura,

Karnataka, India
Corresponding Author: Babaleshwar Vinaykumar Assistant Professor, Dept of orthopaedics, Shri B M Patil Medical College Hospital and Research Institute BLDE (DU) Vijyapura, Karnataka, India

\section{Clinical outcome and complications of comminuted midshaft clavicle fractures treated with anatomical locking compression plate-a prospective study}

\author{
Dr. Naik Sandeep, Babaleshwar Vinaykumar and Nandi Santosh
}

DOI: https://doi.org/10.22271/ortho.2019.v5.i4d.1673

\begin{abstract}
Fractures of the clavicle is one of the most common injures of human skeleton which used to be traditionally treated non-operatively. The present study was undertaken to evaluate the functional outcome in displaced midshaft comminuted clavicle fractures treated with anatomical locking compression plate. 40 patients included in the study between December 2016 to January 2018 with displaced comminuted midshaft clavicle fractures were treated surgically with anatomical locking plate and screws. 34 fractures united at an average of 11.24 weeks, 4 patients had delayed union, 2 patients had plate loosening and 3 patients had implant prominence and irritation. The functional outcome according to Constant and Murleyscore after fracture union in surgically treated midshaft one third clavicle fractures were excellent in 30 patients, good in 6 patients and fair in 2 Patient and poor in 2 patient. This study shows rigid fixation with anatomical locking compression plate and screws for displaced comminuted mid shaft clavicle fractures has excellent to good functional outcome in $90 \%$ of the cases and progress to predictable union and has acceptable complications rate.
\end{abstract}

Keywords: clavicle - injuries, fractures- fixation, anatomical locking compression plate.

\section{Introduction}

Midshaft comminuted clavicle fracture is one of the most common injuries of the skeleton, representing $3 \%$ to $5 \%$ of all fractures and $45 \%$ of shoulder injuries. Open clavicular fracture is an absolute rarity, found in only $0.1 \%$ to $1 \%$ of cases. The rate of midclavicular fractures is more than twice as high in men as in women. The peak incidence occurs in the third decade of life ${ }^{[1]}$.

The most commonly used system of classification of clavicular fractures is that of Allman. It is divided into 3 Groups. 2 Group I: Middle-third fractures, Group II: Lateral-third fractures, Group III: Medial- third fractures.

The incidence of nonunion of midclavicular fractures is usually quoted as being from 0.1 to $0.8 \%$, and the mainstay of treatment has long been non operative. These data, however, are based on studies in which clavicle fractures were not adequately classified regarding patient age and fracture displacement. More recent data, based on detailed classification of fractures, suggest that the incidence of nonunion in displaced comminuted midshaft clavicular fractures in adults is between 10 and $15 \%{ }^{[3]}$.

Also persistent wide separation of fragments with interposition of soft tissue may lead to failure of closed reduction. There is $15 \%$ nonunion rate in widely displaced fractures of middle-third of the clavicle treated without surgery. And all fractures with initial shortening of more than $2 \mathrm{~cm}$ resulted in nonunion ${ }^{[4]}$.

Several studies have examined the safety and efficacy of primary open reduction and internal fixation for completely displaced midshaft clavicular fractures and have noted high union rate with a low complication rate. 5 In a large number of complex clavicle fractures a satisfactory outcome is possible with a low complication rate using a locked compression plate. 6 Primary internal fixation of displaced comminuted mid-shaft clavicular fractures leads to predictable and early return to function ${ }^{[7]}$.

While the overwhelming majority of clavicle fractures are benign, associated life- threatening 
intrathoracic injuries are possible. Complications vary based on location of fracture ${ }^{8}$. Fracture of the clavicle is associated with delayed union or nonunion ${ }^{9}$, brachial plexus compression resulting from hypertrophic callus formation, compression or laceration of the great vessels, trachea, or esophagus, injuries to the neurovascular bundle and the pleural dome, poor cosmetic appearance, pneumothorax and intrathoracicinjury.

There are various methods for treating clavicle midshaft fractures, such as intramedullary K-wires or Steinmann pins fixation and plate fixation. In particular, plate fixation can help obtain firm anatomical reduction in severe displaced or comminuted fracture.

There are various plates including Sherman plates, Dynamic compression plates and Semi tubular plates. Among them, a reconstruction plate and Anatomical locking compression plate (LCP). We have taken up this study to gain a deeper understanding of results and complications associated with this procedure, to evaluate the functional outcome after fixation of displaced clavicular fractures with locking compression plate.

\section{Methodology}

The present study was carried out from $1^{\text {ST }}$ DECEMBER 2016 to $31^{\text {ST }}$ JANUARY 2018 at Orthopaedic Department in Shri B.M.Patil Medical College Hospital and Research Center, Vijayapur. During this period 40 patients of middle shaft comminuted clavicle fractures were treated surgically. Adults above 18 years, Robinson's type 2B1 and 2B2 included for this study. Patients willing for treatment and giving informed and written consent. Patient is below 18 years. Medial third comminuted clavicle fracture, Fractue of lateral third clavicle, Patients not fit for surgery, managed conservatively for other medical reasons, All open fractures of clavicle, Immunocompromised status were excluded from the study. All our cases were operated within 4 days of injury. After obtaining fitness for surgery careful preoperative planning of fixation is done. Patient is placed in beach chair position and operative site painted draped. Transverse skin incision made over the deformity of the fracture and extended on either side aiding the reduction amd plate fixation supraclvicular nerves were preserved throughout the procedure $\mathrm{k}$ wire fixation used for provisional fixation, minimal soft tissue dissection was done fracture was fixed with pre contoured locking compression plate and lag screws were used wherever necessary for additional fixation. Arm was immobilized for 4 weeks and gradual mobilization and arm exercises were started after 4 weeks. Repeat radiographs were taken at the end of 4 weeks to decide on mobilization and to masses union.

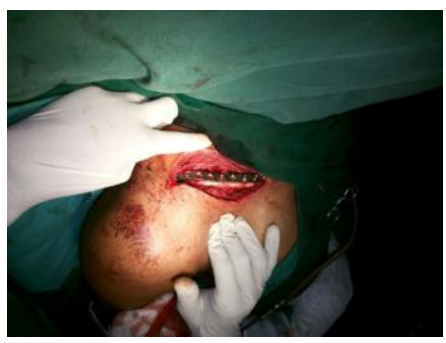

Final fixation

\section{Results}

The present study consists of 40patients of fresh fracture of the clavicle which were treated surgically with Anatomical locking compression plate\& screws for middle third clavicle fracture between $1^{\text {st }}$ December 2016 to $31^{\text {st }}$ January 2018 in
BLDE University SHRI B.M. Patil Medical College Hospital and Research Centre, Bijapur. All the patients were available for follow-up and they were followed at 4 weeks, 3 months, 6 months. Results were analyzed both clinically and radiological for union.

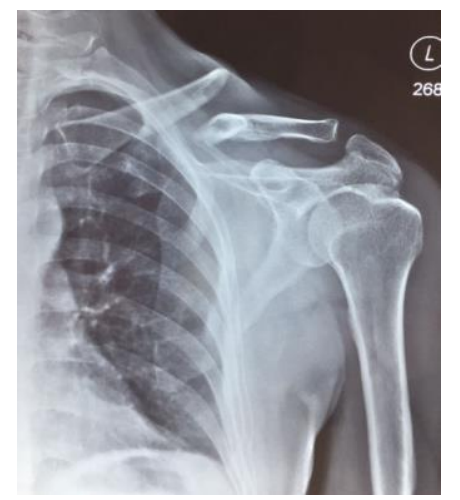

Preoperative comminuted midshaft clavicle fracture

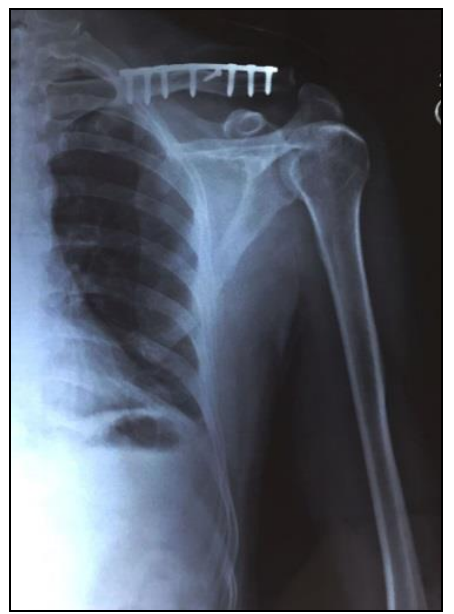

Immediate post-Operative radiograph

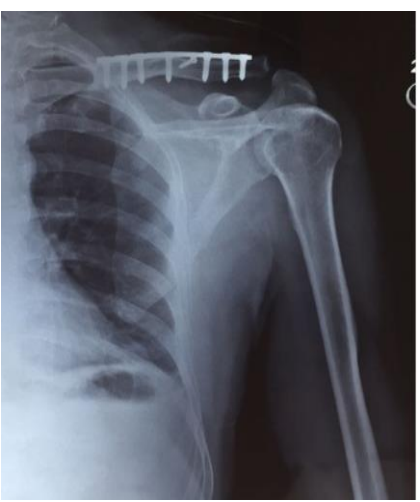

6 weeks post operative xray

\section{Duration of union}

The fracture was considered to be united when clinically there was no tenderness, radiologically the fracture line was not visible and full unprotected function of the limb.

Table 1: Time of Union (Wks) among patients

\begin{tabular}{|c|c|c|}
\hline Time of Union (WKS) & $\mathbf{N}$ & Percent \\
\hline $8-12$ & 37 & 93 \\
\hline$>12$ & 3 & 7.5 \\
\hline Total & 40 & 100 \\
\hline
\end{tabular}




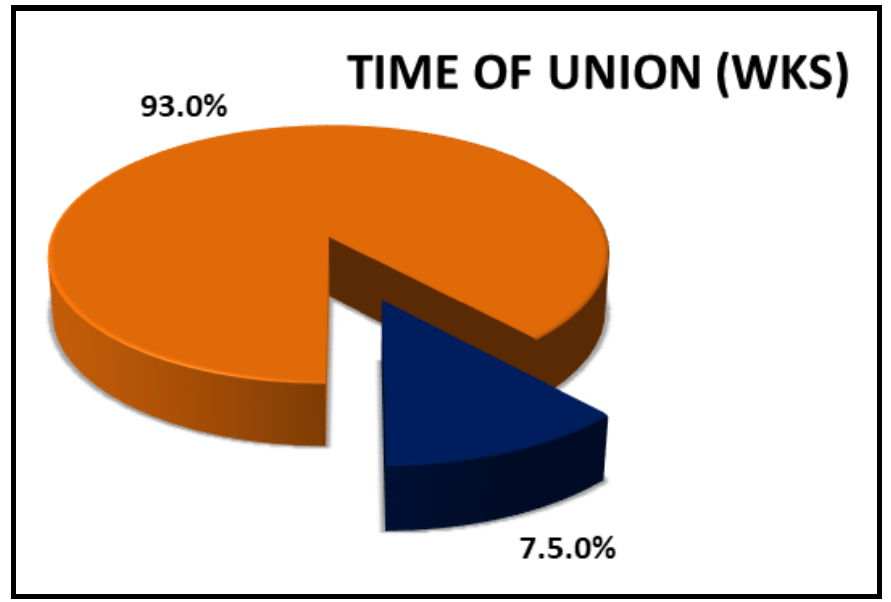

Fig 1: Time of Union (Wks) among patients

In our study 37 patients (> 90\%) united at the end of 12 weeks. Delayed union occurred in $3(7.5 \%)$ patients. All eventually progressed to union at the end of 20 weeks. None of the cases required revision and bone grafting.

\section{Functional Outcome}

The functional outcome is assessed by Constant and Murley score.

Table 2: Results after surgery among patients

\begin{tabular}{|c|c|c|}
\hline Results & N & Percent \\
\hline Excellent & 30 & 75 \\
\hline fair & 2 & 5 \\
\hline Good & 6 & 15 \\
\hline Poor & 2 & 5 \\
\hline total & 40 & 100 \\
\hline
\end{tabular}

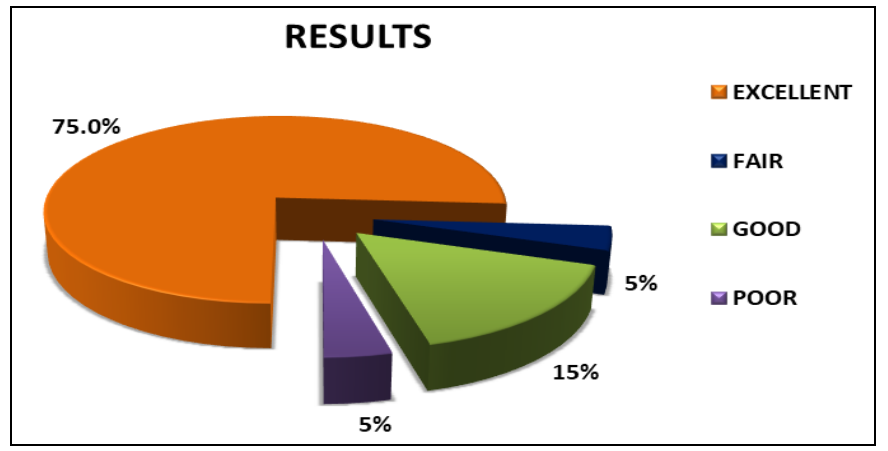

Fig 2: Results after surgery among patients

In this study 30 patients $(75 \%)$ had excellent functional outcome, 6 patients $(15 \%)$ good outcome, 2 patients $(5 \%)$ fair outcomes 2 patients (4\%) poor outcomes.

\section{Complications}

$12.5 \%$ of our cases had complications out of which $7.5 \%$ had plate prominence and irritation for which no intervention was done and were adivised implant removal after the union. 5\% of cases had plate loosening which were kept under observation and extended immobilization protocol. eventually they progressed to union and no further complications. Both these patients were non compliant and did not followed the immobilization for 4 weeks.

\section{Discussion}

Clavicle fractures are usually treated conservatively. In a study conducted to analyze the results of conservative treatment by Hill et al. ${ }^{[10]}$ in 1997, Nordqvist et al. ${ }^{[11]}$ in 1998 and Robinson et al. [12] in 2004 found poor results following conservative treatment of displaced middle third clavicle fracture. There are specific indications like displacement, with or without comminuted middle third clavicle fracture (Robinson Type-2B1, 2B2).

The present study of patients with comminuted midshaft clavicle fractures is compared with Bostman et al ${ }^{[13]}$ study which treated middle third clavicle fractures. In that study totally 103 patients were treated by early open reduction and internal fixation with plate and screws. It was also compared with Cho et al. ${ }^{[14]}$ study where 41 patients with a clavicle midshaft fracture were treated by internal fixation with a reconstruction plate (19 patients) or reconstruction LCP (22patients).

\section{Sex Incidence}

In this study 35 patients (86\%) male and 5 patients (14\%) female. In Bostman et al 13 series also commonly males are affected 76 Patients (73.79\%) compared to females 27 Patients $(26.21 \%)$. In Cho et al 14 study, the reconstruction plate group that 12 male and 7 female Patients and in the locking compression plate group it was 17 male and 5Patients. Male predominance can be drawn from this inference.

\section{Type of fracture}

In this study all Patients with midshaft clavicle fractures were of closed type. This is comparable to Bostman et al. ${ }^{[13]}$ and Cho et al. ${ }^{[14]}$ study which also showed all their patients were closed fractures.

\section{Fracture classification:}

In this present study, Robinson Type-2 B1 (Displaced with simple or butterfly fragment) were more common and there were 18 Patients (36\%). Type-2 B2 (displaced with comminution) occurred in only 32 Patients (64\%).

In Bostman et al. ${ }^{[13]}$ study also Robinson type-2B1 was common in 81 patients $(78.64 \%)$. Robinson type-2 B2 occurred only in 22 patients $(21.36 \%)$.

In Cho et al. ${ }^{[14]}$ study, in reconstruction plate group there were 7 Patients with B1 type and 12 Patients with B2 type and that of the locking compression group had 9 B1 type and 13 B2type.

\section{Time interval for surgery}

All our patients were operated within 4 days of admission.

In Bostman et al. ${ }^{[13]}$ study all the patients were operated within 3 days of injury. In Cho et al. [14] study, the reconstruction plate group was operated by 4 days and that of locking compression plate was 9days.

\section{Duration of union}

In this study majority of the comminuted midshaft clavicle fracture cases united between 8 to 12 weeks (>90\%). In 3 Patients $(7.5 \%)$ delayed union occurred as there was a displaced butterfly fragment which united with the main fragment at the end of 16 weeks. There were no non-union. Lazarus MD [15] stated radiological union occurred approximately between 6 to 12 weeks.

In Cho 14 et al. study, bony union for reconstruction plate was 14.6 weeks and that of locking compression plate was 13.2 weeks.

\section{Complications}

There were no major complications in this study. Both 
Bostman et al. and Cho et al. ${ }^{[13}$ 14] didn't have any major complications either.

\section{Plate loosening}

Plate loosening occurred in 3 Patient $(7.5 \%)$ at the end of 4 weeks postoperatively. The cause in this patient was also due to non compliance with the post operative protocol. The patient went for farming in the field before the fracture union. With further advise of not to lift heavy weights in the affected limb clavicle fracture went to unite in mal position at end of 12 weeks and no reoperation was performed for this.

In Bostman et al. ${ }^{[13]}$ study 7 patients $(6.80 \%)$ had implant loosening. In all the patients loosening occurred at 6 postoperative weeks. Malunion of varying degree followed in all of these patients and no reoperations were performed.

In Cho et al study ${ }^{[14]}$, only there construction group that plate loosening in 3 Patients $(15.8 \%)$

\section{Delayed union}

Delayed union occurred in 2 Patients $(5 \%)$ due to a large butterfly fragment in the inferior aspect of clavicle which went on to unite with the main fragments at the end of 16 weeks. In Bostman et al. ${ }^{[13]}$ study delayed union occurred in 3 Patients $(2.91 \%)$.

\section{Skin complications}

There was no skin complication. The total complication in this study were $15 \%$ excluding skin related minor complications. The total complication rate of Bostman et al. ${ }^{[13]}$ study was $23 \%$.

\section{Functional outcome}

The functional outcome according to Constant and Murley 16 in this study of total 40 Patients of fresh middle third clavicle fracture fixed with locking compression plate and screws showed excellent results in 30 Patients $(75 \%)$ and good functional outcome in patients 6 Patients (15\%). Fair functional outcome in 2 Patient $(5 \%) \&$ poor results in 2 patients $(5 \%)$ The advantage of rigid internal fixation and early mobilization of fresh displaced clavicle fracture is that it (displaced comminuted middle third) gives immediate pain relief and prevents the development of shoulder stiffness and non-union.

\section{Conclusion}

Operative treatment of clavicle fractures generally have good functional outcome. The advantages of Anatomical locking compression plate include strong fixation due to locking between the screw and plate, and blood supply pre servation due to minimal contact between plate and cortical bone. Surgery time can be reduced using anatomical locking compression plate because accurate plate contouring is not necessary and periosteal stripping could be minimized using self-tapping screws. Surgical scars are currently considered major complications due to the increasing demand for aesthetics. In conclusion, bony union could be achieved with anatomical locking compression plate clavicle and the clinical outcomes were satisfactory and complications were mionor and rates were predictable and comparable to other studies. All the fractures united and there was no non union. More than $90 \%$ have excellent outcome

\section{Reference}

1. Schiffer G, Faymonville C, Skouras E, Andermahr J, Jubel A. Midclavicular fracture: Not just a trivial injury - current treatment options. Dtsch Arztebl Int. 2010; 107(41):711-7.

2. Robert Bucholez, James D Heckman. Charles CourtBrown, Rockwood Green's Fractures In Adults Volume 1 $6^{\text {th }}$ Edition, 2006, 1213-1216.

3. Wun-Jer Shen MD, Tsung-Jen Liu MD, Young-Shung Shen MD. Po-Cheng Orthopaedic Institute, 100 Po-Ai 2nd Road, Kaohsiung, 813, Taiwan. Plate Fixation of Fresh Displaced Midshaft Clavicle Fractures, J Bone Joint Surg [Br]. 2008; 90- B:1495-B

4. Terry Canale S, James H Beaty, Campbell's Operative Orthopedics $11^{\text {th }}$ Edition, 3, 3371-3376.

5. Stegeman et al. Displaced Midshaft Fractures of the Clavicle: Non-Operative Treatment versus Plate Fixation (Sleutel-TRIAL). A Multicentre Randomised Controlled Trial. BMC Musculoskeletal Disorders. 2011; 12:196.

6. Modi N, Patel AD, Hallam Norfolk P, Norwich. University Hospital NHS Foundation Trust, Norwich, UK. Outcome Of 62 Clavicle Fracture Fixations With Locked Compression Plate: Is This The Right Way To Go? doi:10.1016/j.injury.2011.06.266.

7. WgCdr V Kulshrestha, Primary Plating of Displaced Mid-Shaft Clavicular Fractures. MJAFI 2008; 64:208211.

8. McKee MD, Wild LM, Schemitsch EH. Midshaft malunion of the clavicle. J Bone Joint Surg Am. 2003; 85:790-7.

9. Jupiter JB, Leffert RD. Non-union of the clavicle. Associated complications and surgical management. J Bone Joint Surg Am. 1987; 69:753-60.

10. Hill JM, Mc Guire MH, Crosby LA. Closed treatment of displaced middle third fractures of the clavicle gives poor results. J Bone Joint Surgery (Br). 1997; 79:537-540.

11. Nordgvist A, Petersson CJ, Redlund-JohnellI. Mid clavicular fractures in adults: end result study after conservative treatment. J Orthop Trauma. 1998; 12:572576.

12. Robinson CM, Court Brown CM, McQueen MM, Walkefield AE. Estimating the risk of non union following non operative treatment of a clavicular fracture. J Bone Joint Surgery (Am). 2004; 86:13591365.

13. Bostman O, Manninen M, Pihlajamaki H. Complications of plate fixation in fresh displaced mid clavicular fractures. J Trauma. 1997; 43:778-783.

14. Chul-Hyun Cho, Kwang-Soon Song, Byung-Woo Min, Ki-Cheor Bae, Kyung-Jae Lee. Reconstruction Plate versus Reconstruction Locking Compression Plate for Clavicle Fractures. Clinics in Orthopedic Surgery. 2010: 2:154-159.

15. Lazarus. Fractures of the Clavicle. Chapter-26, In: Bucholz RW and Heckman JD, editors, Rockwood and Green's fractures in adults, 5thedition, Philadelphia: Lippincott Williams and Wilkins, 2001, 1041-1078.

16. Constant CR, Murley AHG. A clinical method of functional assessment of the shoulder. Clinical Orthopaedics and Related Research. 1987; 214:160-164. 